\title{
Analysis of fire resistance of cement mortars with mineral wool from recycling
}

\author{
Carolina Piña Ramírez ${ }^{\mathrm{a}, *}$, Alejandra Vidales Barriguete ${ }^{\mathrm{b}}$, Rubén Serrano Somolinos ${ }^{\mathrm{c}}$, \\ Mercedes del Río Merino ${ }^{\mathrm{a}}$, Evangelina Atanes Sánchez ${ }^{\mathrm{d}}$ \\ a Polytechnic University of Madrid, Superior Technical School of Building, Department of Architectural Constructions and their Control, Spain \\ ${ }^{b}$ Polytechnic University of Madrid, Superior Technical School of Building, Department of Building Technology, Spain \\ ${ }^{c}$ Polytechnic University of Madrid, Superior Technical School of Building, Spain \\ d Universidad Politécnica de Madrid, Escuela Técnica Superior de Ingeniería y Diseño Industrial, Departamento de Ingenieria Mecánica, Química y Diseño Industrial, Ronda de \\ Valencia 3, 28012 Madrid, Spain
}

\section{H I G H L I G H T S}

- Waste mineral fibres are an alternative to the reinforcement fibres used nowadays.

- After the test mortars reinforced with mineral fiber waste improve thermal properties.

- It is possible to replace large amount of the volume of sand used by mineral fiber waste.

- Mortars with fibre residues after the fire test maintain its mechanical properties.

Keywords:

Mineral wool

Cement mortar

Recycling

Fire resistance

Construction and demolition waste

\begin{abstract}
A B S T R A C T
The objective of this research is to analyse the fire resistance of cement mortars with mineral wool from construction and demolition waste (CDW) recycling. The recycled mortars are therefore exposed to direct fire reaching a maximum temperature of $700^{\circ} \mathrm{C}$, and an experimental plan is designed to analyse thermomechanical behaviour before and after the testing of the mortars with different types of recycled fibres. The results show that the surface hardness of all mortars is practically unchanged after the fire, whereas the incorporation of fibre residues produce a significant improvement in the flexural strength after fire test compared with the reference mortar. The compressive strength values of all mortars decrease after the fire although they remain at optimum values for use according to regulatory requirements. The values of thermal conductivity are lower or remain unchanged after the fire test. Results show that the addition of these recycled fibres can be a sustainable alternative to the commercial ones currently being used, improving mechanical-thermal behaviour after the fire and preventing the explosive behaviour of the mortars.
\end{abstract}

\section{Introduction}

Objective 13 of the United Nations 2030 Agenda for Sustainable Development requires urgent measures to be taken to combat climate change and its impact on the planet. To this effect, the circular economy is presented as the main response to the challenges faced in terms of efficiency and sustainability of natural resources, proposing alternative production and consumption practices that directly affect the environmental impact of both construction

* Corresponding author at: Technical University of Madrid, Avda. Juan de Herrera, 6, 28040 Madrid, Spain.

E-mail address: carolina.pina@upm.es (C. Piña Ramírez). resources and waste [1]. The new EC circular economy legislation has encouraged European institutions and Member States to promote the recycling and recovery of waste [2], in order to minimise the consumption of raw materials as well as waste destined for landfill [3].

The amount of raw materials extracted, harvested and consumed worldwide HAS increased by $60 \%$ since 1980 , according to the OECD, mainly for the construction sector [4]; about 3 billion tons of raw materials are used to manufacture building products worldwide.

In Spain, in particular, the use of aggregates for construction grew by $10.5 \%$ in 2017 , to 12 million tons [5], and quarries pro- 
duced 40.8 million tons of industrial aggregates for manufacturing binders and other products.

In this research, cement mortars are made by replacing as much aggregate as possible with construction and demolition waste, which is a good solution for recycling and minimising the use of raw materials used.

More specifically, the aim is to recycle mineral wool residues from insulating materials found in construction and demolition waste, since the growing importance of thermal insulation in the construction sector [6] has led to an increase in the use of mineral wool and therefore its waste. This ensures that non-recyclable mineral wool waste is not unusable and is a valuable resource through its recovery and an alternative to the reinforcing fibres currently used [7].

On many occasions, cement mortars are used in masonry as coatings for other materials that can be compromised in the event of a fire [8], because they are non-combustible and therefore a good insulator [9]. Consequently, this research underlines the importance of understanding the behaviour of mortars made with mineral wool residues in post-heating, to see if both their thermal and mechanical behaviour enable the functionality of the construction to be maintained.

There are numerous investigations that analyse the fire resistance of cement mortars with different additions, since their mechanical properties can be affected although it is known that they can withstand high temperatures due to their low thermal conductivity and high specific heat $[10,11]$. Pozzolans are used as additions in most investigations of the fire resistance of mortars $[12,13]$, but the mechanical benefits of the compounds when adding other types of fibres have also been proven [14-16].

There are studies that indicate that cement-based compounds can be detached upon exposure to fire for two reasons; firstly, due to the thermomechanical process and the difference in thermal expansion between the cement matrix and the aggregate [17], and secondly, due to the accumulation of high pressures in the porous network of the material [18]. This research also provides evidence of how it affects the incorporation of mineral wool residues in the explosive behaviour of mortars.

For all these reasons, and although there are studies on the behaviour of reinforced cement mortars in the presence of fire [9], none have been found that study the impact of fire on mortars incorporating mineral wool residues subjected to a direct fire test and comparing their mechanical and thermal properties before and after a fire.

In a fire, cement mortar is an inert element that only absorbs part of the heat generated while other materials can produce gases, heat, etc. Therefore, it is considered of great importance to analyse the impact of fire on the ecological cement mortars proposed in this research, in order to study the feasibility of using recycling fibres for their reinforcement from the point of view of their behaviour in response to a fire.

\section{Materials and methods}

\subsection{Materials}

The following materials were used to carry out the experimental development of the research:

- Portland Cement type CEM II / B-L $32.5 \mathrm{~N}$ (supplied by the company Cementos Portland Valderrivas, Madrid, Spain), in accordance with the UNE-EN 197-1:2011 and RC-08 standards $[19,20]$.
- The fine aggregate was a natural sand that was used in a dry condition, with a diameter of $4 \mathrm{~mm}$, according to standard UNE-EN 13139/AC:2004 [21].

- The water used came from the Canal de Isabel II of Madrid that has the technical characteristics established in the standard UNE EN 13279-2 [22].

- Three different types of mineral wool waste have been used, all of them from the Center for the Integral Treatment of Construction Waste and Demolition of the N-1 Motorway towards Irún $\mathrm{Km} \mathrm{40,} \mathrm{located} \mathrm{in} \mathrm{the} \mathrm{town} \mathrm{of} \mathrm{El} \mathrm{Molar} \mathrm{in} \mathrm{the} \mathrm{Community} \mathrm{of}$ Madrid, and managed by the company GEDESMA S.A. Subsequently, the rock wool (RW) and fiberglass (FG) residues have been selected and separated, and another sample of the mixed mineral wool waste (MIX) has been kept unselected, as they were in the landfill.

- No additives were used.

The three types of mineral fibre residues underwent pretreatment: they were crushed in a Cutting Mill Retsch M 100 with a $1.5 \mathrm{~kW}$ motor and a rotor speed of $1,500 \mathrm{rpm}$, for 3 intervals of $3 \mathrm{~min}$ each, in order to obtain a suitable format for incorporation into the cement matrix (between $500 \mu \mathrm{m}$ and $1000 \mu \mathrm{m}$ in length determined by SEM microscopy in previous studies) [23].

\subsection{Preparing test specimens}

To achieve the objective of the study, a series of prismatic specimens measuring $40 \times 40 \times 160 \mathrm{~mm}$ (three specimens per series) were rigorously prepared, according to UNE EN1015-2:2012 and UNE EN1015-11:2000 standards [24,25]. Although the regulation does not contemplate the manufacture of mortars with fibre, the procedure mentioned therein was followed through rigorous and standardised testing, so that the study can be reproduced and the tests may be comparable in future research. The environmental conditions of the laboratory were $22 \pm 2{ }^{\circ} \mathrm{C}$ of average temperature and $48 \pm 5 \%$ of the relative humidity of the air.

The dosage of all specimens expressed in mass was 1:3:0.6 (cement: sand: water), and the fibre added instead of river sand, measured in volume, was $50 \%$ of each waste (Table 1), since it was found that mortars with a fibre percentage higher than $50 \%$ were not workable.

For the manufacture of the composite materials, fibres were added to the water first of all, then the cement, which were manually kneaded to ensure the correct distribution of the fibres (Fig. 1). Then, they are fed into the IBERTEST CIB-701 vertical axis mixer, updated to IB32-040 V0, which mixes the components at low speed for $15 \mathrm{~s}$, and then the aggregate is incorporated and the mixture is rapidly kneaded for $75 \mathrm{~s}$. Once the mixtures have been prepared, their plastic consistency is guaranteed by measuring the spill value, according to the methodology described in the UNE EN-1015-3 standard [26].

After $24 \mathrm{~h}$, the specimens were demoulded and cured in a humid chamber at a temperature of $20{ }^{\circ} \mathrm{C}\left( \pm 2^{\circ} \mathrm{C}\right)$ and a relative humidity of $95 \%$ for 28 days, before carrying out the research tests.

\subsection{Experimental plan}

The experimental plan was designed in three phases, with Phase 1 and Phase 3 being carried out in the materials laboratory of the Higher Technical School of Building of the Polytechnic University of Madrid, and Phase 2 in the facilities of the Fire Prevention and Extinction Service of the Community of Madrid. 
Table 1

Composition of compounds.

\begin{tabular}{lllll}
\hline Name & Cement $(\%)$ & Sand $(\%)$ & Water $(\%)$ & Fibre $(\%)$ \\
\hline REFERENCE & 33.33 & 100.00 & 20.00 & 0.00 \\
$50 \%$ RW & 33.33 & 50.00 & 20.00 & 50.00 \\
$50 \%$ FG & 33.33 & 50.00 & 20.00 & 50.00 \\
$50 \%$ MIX & 33.33 & 50.00 & 20.00 & 50.00 \\
\hline
\end{tabular}
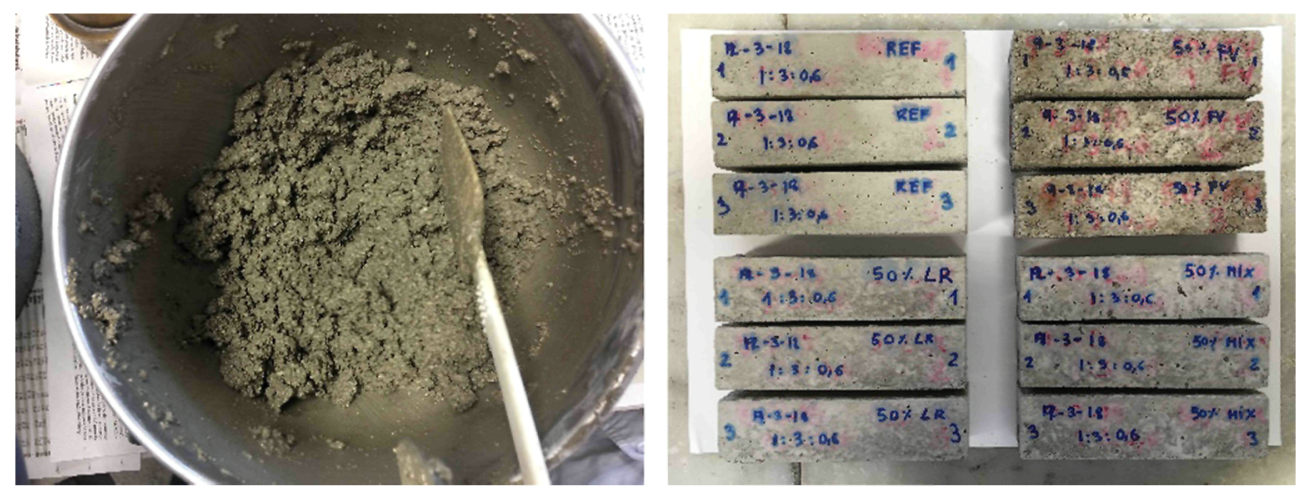

Fig. 1. Manual kneading and prismatic specimens.

2.3.1. Phase 1: mechanical and thermal tests of mortars with fibres added before the fire test

Shore D hardness, flexural and compression strength tests were performed following the methods described in a previous work [7], and the thermal conductivity of the mortars manufactured with the three types of fibre residues was calculated before exposing them to fire.

Shore D Hardness (UNE-EN 10204) [27]: a hardness tester measuring Shore D Hardness was used on the two longitudinal sides of the specimens.

Flexural and Compression Strength (UNE-EN 1015-11) [25]: Ibertest Autotest 200 work equipment was used, and a progressive and constant speed load is applied until breakage and the value obtained is recorded.

Thermal conductivity (UNE EN-10456:2012) [28]: a TCi Thermal Conductivity Analyser from C-TERM Technologies was used. The instrument uses an interfacial single-sided heat reflectance sensor which applies a constant and momentary heat source to the sample, in order to measure both its thermal conductivity and diffusivity (Fig. 2).

\subsubsection{Phase 2: fire resistance test}

Prismatic specimens measuring $40 \times 40 \times 160 \mathrm{~mm}$ are manufactured and after 28 days their resistance to direct fire is tested.

Fire resistance was determined according to the instructions contained in the UNE-EN 1363-1 standards: 2012, UNE-EN 13632: 2000, UNE-EN 1365-4: 2000 and ISO R-834 [29-32].

The test was carried out in accordance with ISO R-834 standard, which considers a calorific potential of $40 \mathrm{~kg}$ of wood per square metre $\left(\mathrm{kg} / \mathrm{m}^{2}\right)$, equivalent to the average calorific value in the formation of fires. To perform the test, the prismatic specimens were placed horizontally on a $1 \mathrm{~m}^{2}$ steel grill, leaving all sides in direct contact with the fire (Fig. 3). The 3 specimens of each sample are placed on the grill so that each compound has a sample in the area furthest away from the fire, in the innermost area and in the intermediate area. The fire was started by spraying pinewood with petrol to cause combustion. The test lasted $1 \mathrm{~h}$, and the temperature was measured at 3 points on the surface of the specimens every 5 min, using a compact infrared thermometer model "Testo 845".
After 1 full hour of exposure to fire, the samples were left to cool slowly on the grill.

Thermal camera images were also captured at different times throughout the test (Fig. 4).

\subsubsection{Phase 3: mechanical and thermal tests of mortars with fibres} added after the fire

Once cooled, the specimens were again subjected to the Shore D surface hardness, flexural and compressive strength and thermal conductivity tests, to compare the resistance losses suffered after the fire (Fig. 5).

\section{Results and discussion}

Fig. 6 shows the test specimens exposed to direct flames; some of these reached a temperature of up to $700^{\circ} \mathrm{C}$ in less than $15 \mathrm{~min}$ (with an external ambient temperature of $3.6^{\circ} \mathrm{C}$ in the area where the grill was placed), as in similar studies [33].

It should be noted that two of the three reference specimens exploded during the first $15 \mathrm{~min}$ of the test, which shows, as stated by other authors [13] that the incorporation of fibres is effective in preventing the explosive detachment of mortars.

The evolution of the surface temperature of the specimens with respect to the test time can be seen in Fig. 7 . The reference mortar and those with the three different types of mineral wool residues were analysed. As it can be seen, the specimens reach their maximum temperatures between 15 and $30 \mathrm{~min}$ after the start of the fire, reaching peaks of up to $700{ }^{\circ} \mathrm{C}$ for the reference mortar and between 550 and $600{ }^{\circ} \mathrm{C}$ for those with fibre residues.

These results indicate that the reference samples without the addition of residues suffered a greater impact from the fire than those with mineral wool residues. The mortars containing rock wool residues reached the highest maximum temperatures (up to $600{ }^{\circ} \mathrm{C}$ ) and those containing mixed mineral wool residues the lowest $\left(449.9^{\circ} \mathrm{C}\right)$.

This may be due to the fact that, as indicated by other authors [18], when fibres are melted in cement masses, a series of channels are created that allow air to be evacuated, releasing pore pressure and therefore reducing the temperature and cracks produced in the cooling phase. 

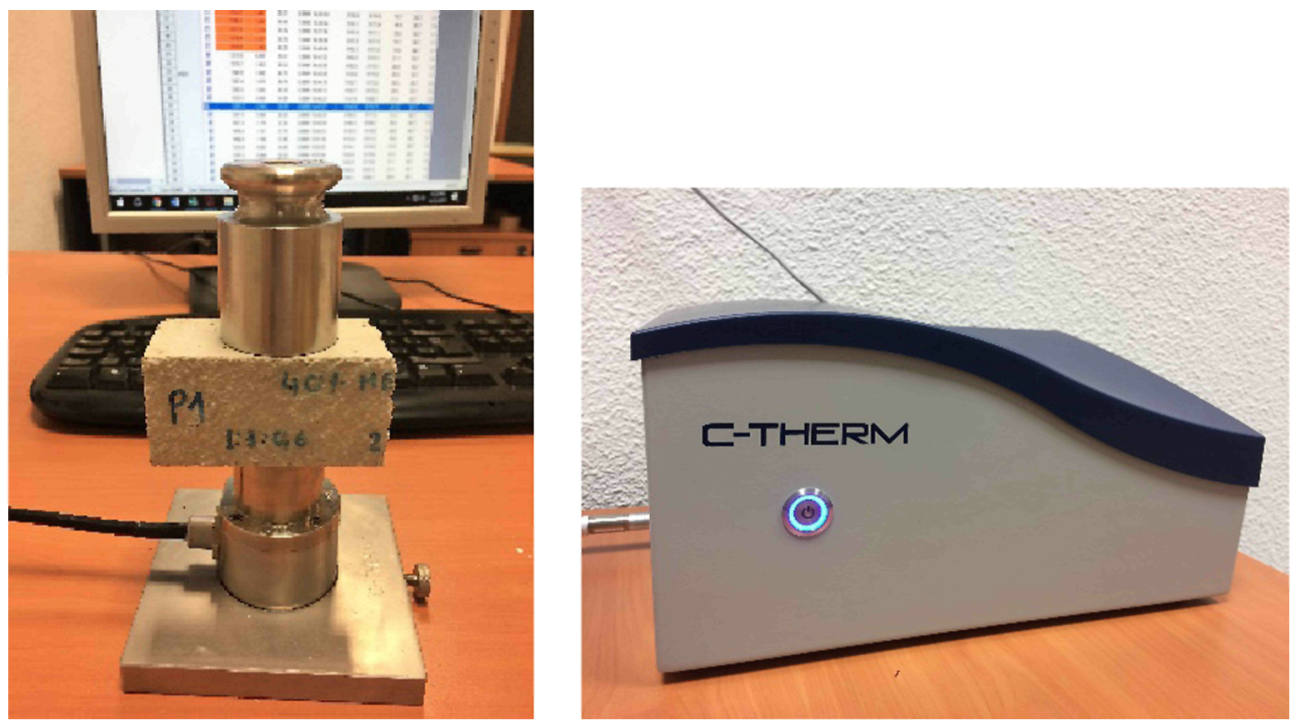

Fig. 2. Interfacial single-sided heat reflectance sensor (left), and TCi Thermal Conductivity Analyser (right) used for thermal conductivity test
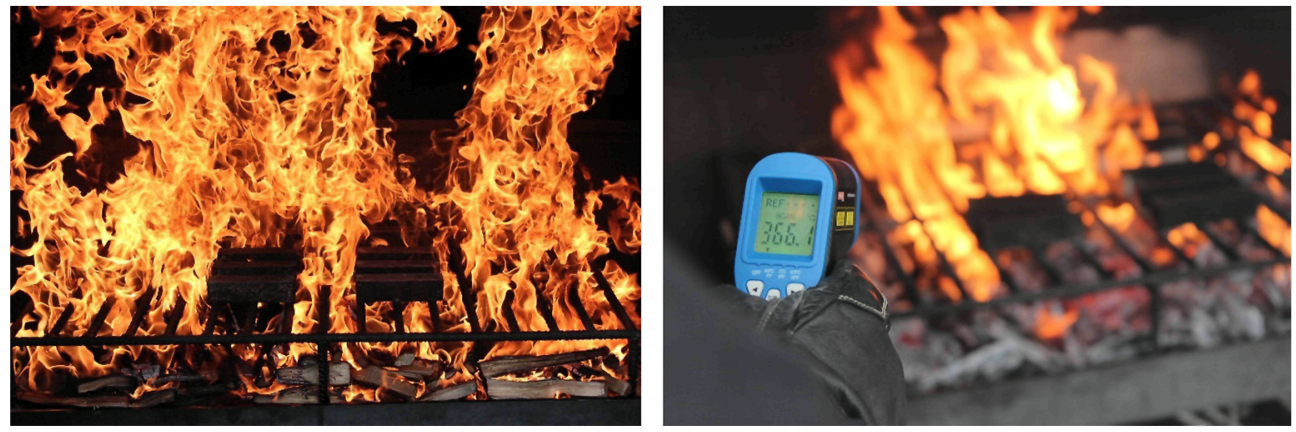

Fig. 3. Resistance to direct fire test and temperature measurement with an infrared thermometer.
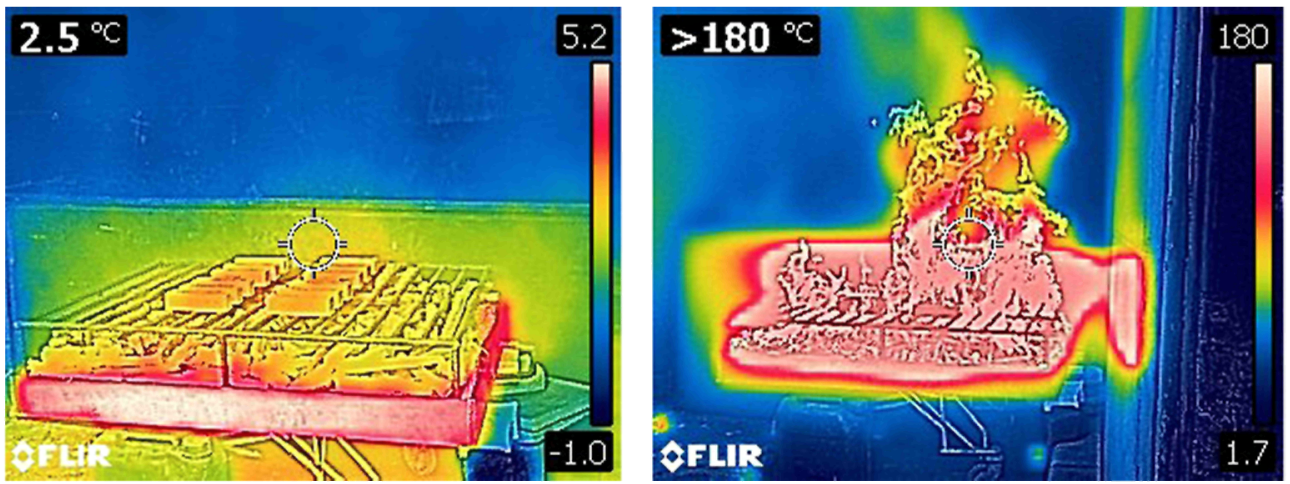

Fig. 4. Thermographic images of the start of the fire.

Mortars with fibreglass and mixed residues reach lower temperatures due to the increase in porosity [9] although the cooling process is slower than the reference mortars, which cool down faster.

This result is consistent with that obtained in previous studies by the authors, which showed how the mortars containing fibres had a greater pore volume than the reference mortars, the highest values being for mortars with fibreglass and mixed waste [23].

Fig. 8 shows the results obtained in the Shore D surface hardness test before and after the fire test, for the mortars with fibre residues and the reference mortar.
As you can see, the surface hardness of the mortars is practically unchanged after the fire, and all of them maintain similar values to those observed in other studies [34].

It should be noted that, in any case, the worst performance due to percentage loss of surface resistance is presented by specimens containing mixed mineral wool residues, in which there is a minimum decrease in the value of this surface hardness of less than $2 \%$; this could be attributed to a less homogeneous connection of the two types of fibres with the matrix.

Fig. 9 contains a graph showing the results obtained for flexural strength, before and after the fire test, for the mortars with fibre 

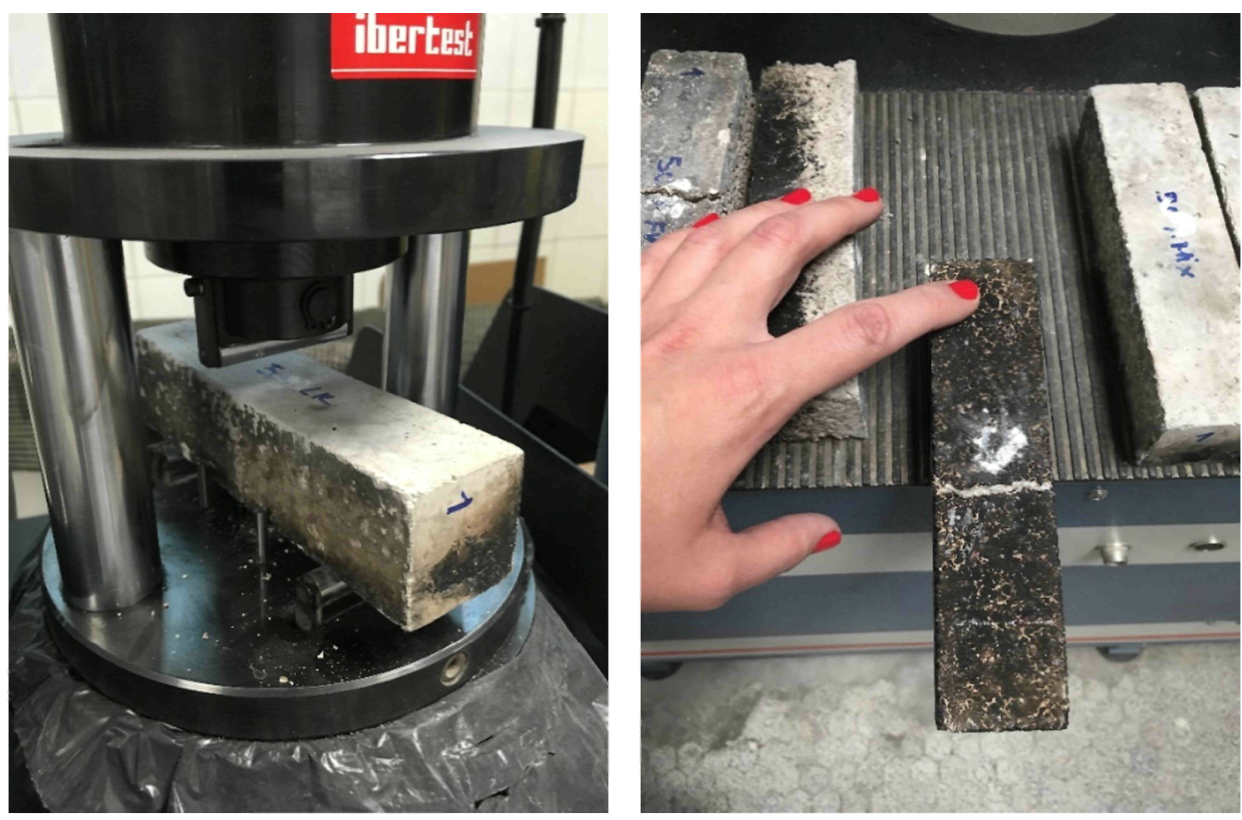

Fig. 5. Ibertest Autotest 200 used for Flexural and Compression Strength test (left) and the compound after the fire once tested (right)
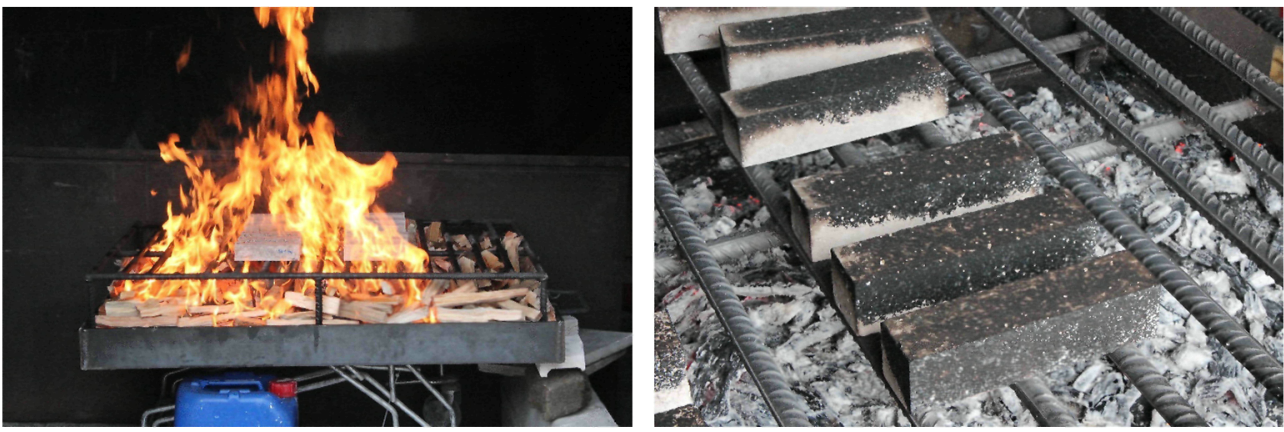

Fig. 6. Fire resistance test on compounds. Left: ignition. Right: cooling.

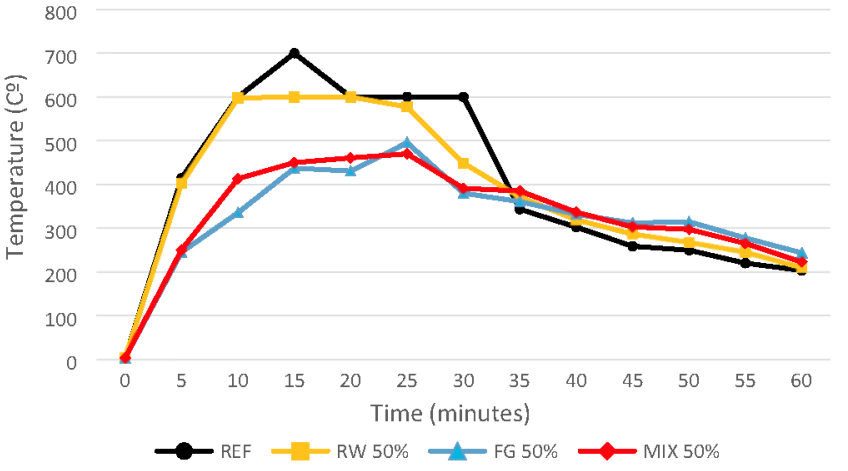

Fig. 7. Evolution of the average temperature with respect to the exposure time of both reference and reinforced specimens with the three types of fibre residues.

residues and the reference mortar. It shows that the flexural strength of the mortars worsens significantly after the fire test. It should be noted that the reference mortar exhibited the worst flexural behaviour after the fire, with a decrease in resistance of up to $92.7 \%$, while mortars with fibre residues maintained acceptable resistance values.

It shows that mortars with mineral wool residues do not register a decrease in resistance of over $50 \%$ for any of the three types of residues, which all remain at very similar values. This demon-

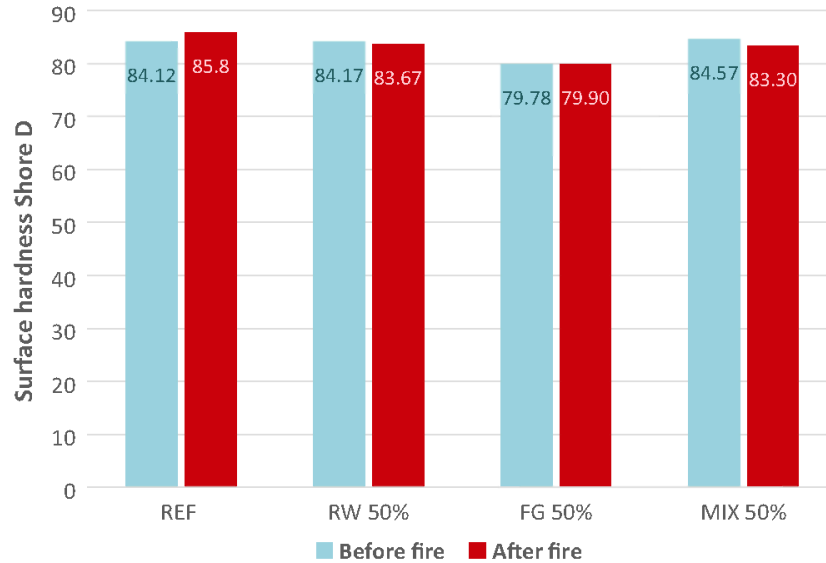

Fig. 8. Surface hardness values of mortars.

strates that the incorporation of fibre residues in mortars can produce a significant improvement in their behaviour against fire, just as some authors demonstrated for other types of fibres such as steel or polypropylene $[18,35]$.

Fig. 10 shows a comparison of the behaviour of mortars in terms of their compressive strength, before and after being exposed to 


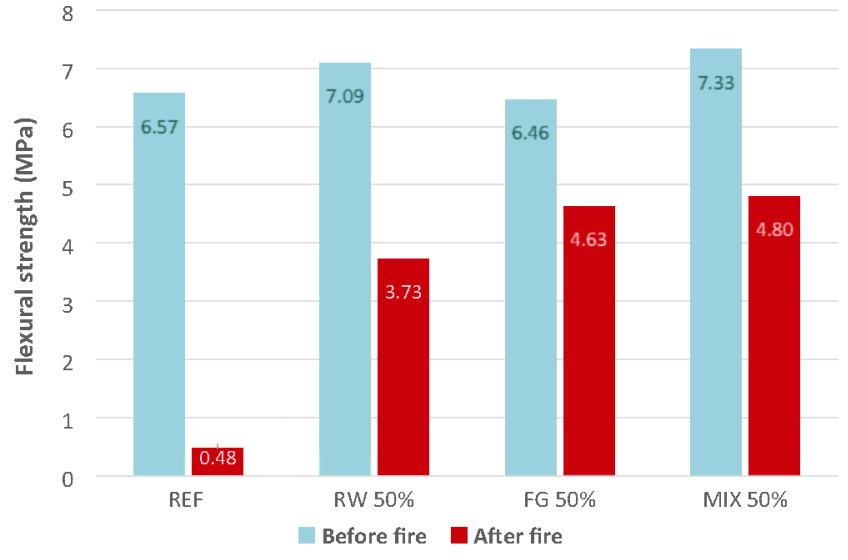

Fig. 9. Flexural strength values of mortars.

fire, both for those with fibre residues and the reference mortar. Pre-fire values show that the compressive strength of the reinforced mortars decreases against the unreinforced matrix due to an increase in porosity of the compound $[15,18]$. This result could also be attributed to the higher porosity values of mortars with added fibres compared to the reference mortar [23].

It can be seen that the compressive strength values of the mortars decrease after the fire, with the mortar with rock wool residue showing the greatest decrease of up to $45.41 \%$. However, despite this decrease, the compressive strength values of all ready-made mortars remain at optimum values for use according to regulatory requirements, which establish acceptable values between $0.4 \mathrm{~N} / \mathrm{mm}^{2}$ and $7.5 \mathrm{~N} / \mathrm{mm}^{2}$, admitting higher values (UNE-EN 998-1) [36].

Fig. 11 shows the results of the thermal conductivity coefficients $(\lambda)$ of the mortars made with fibre residues and the reference mortar, before and after the fire test, allowing their capacity to transfer conduction heat to be analysed. As expected, mortars incorporating fibre residues have lower thermal conductivity values than the reference mortar, and therefore a better insulating capacity $[1,37,38]$. This result is in line with previous studies [23], since the aforementioned increase in pore volume of reinforced mortars with respect to the reference mortar leads to a decrease in apparent density and bulk, which in turn leads to a decrease in thermal conductivity. Also, it is known the thermal insulation characteristics of mineral fibres due to is low thermal conductivity; this fact could also contribute to the reduction of

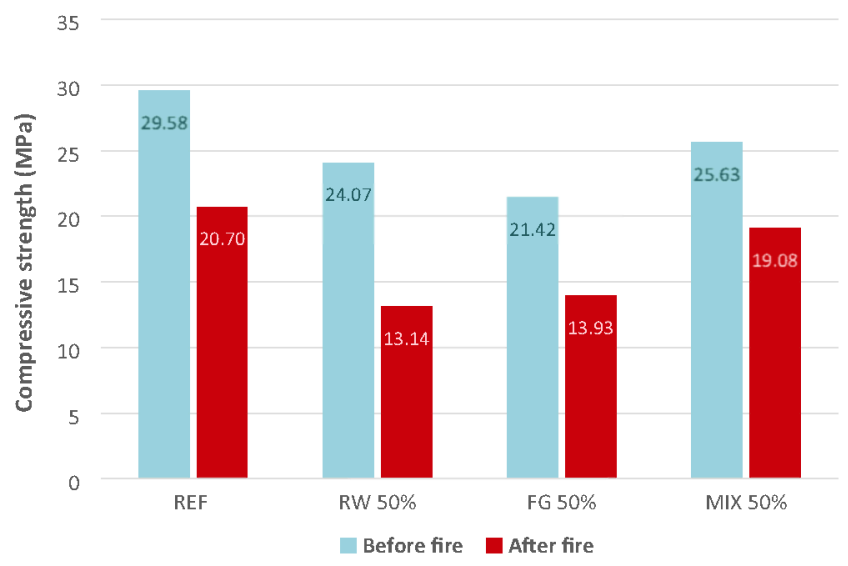

Fig. 10. Compressive strength of mortars.

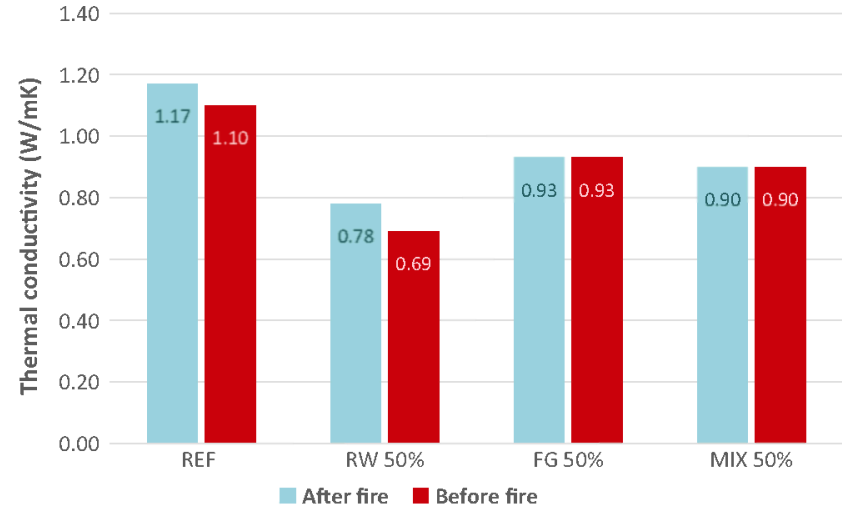

Fig. 11. Thermal conductivity of mortars.

the thermal conductivity of mortars containing fibres compared with reference mortar.

It can be seen that the reference mortars and those made with rock wool have better thermal behaviour after the fire test, since they have lower values of thermal conductivity, while thermal conductivity values remain unchanged for those containing fibreglass and mixed mineral wool residues. The mortars with the addition of rock wool residue are the most insulating after the fire test, reaching very low values of thermal conductivity of up to $0.69 \mathrm{~W} / \mathrm{mK}$.

\section{Conclusions}

The analysis of the results obtained in the study of resistance to direct fire of mortars made with mineral wool residues shows that they have demonstrated good fire behaviour, since the incorporation of these fibre residues allows adequate mechanical properties to be maintained for their use and prevents the explosive detachment of mortars. Cement-based construction materials are designed primarily to resist compressive stress, and these ecological mortars have values higher than $13.14 \mathrm{MPa}$ for all cases, being well above the acceptable regulatory values.

This research shows that cement mortars with mineral wool residues do not burn, so they do not add more load to the fire nor do they release asphyxiating gases and fumes in case of fire. It also shows that they remain resistant at temperatures of up to $700^{\circ} \mathrm{C}$ and have very low thermal conductivity, so in addition to not collapsing, they would be able to protect other elements of combustible materials and thus prevent fires from spreading.

The incorporation of mineral wool residues as reinforcement in cement-based mortars is a viable and sustainable alternative in terms of fire behaviour, since their manufacture enables the recycling of up to $50 \%$ of the volume of sand used, which means a large amount of raw material savings and high volume recycling of mineral wool.

For all the above reasons, it can be deduced that mortars with fibre residues after the fire test not only maintain mechanical properties, making them suitable for use, but also improved thermal properties, which may make them an alternative to the reinforcement fibres used nowadays.

\section{CRediT authorship contribution statement}

Carolina Piña Ramírez: Conceptualization, Methodology, Writing - original draft, Investigation. Alejandra Vidales Barriguete: Resources, Visualization. Rubên Serrano Somolinos: Methodology, Resources. Mercedes del Río Merino: Supervision. Evangelina Atanes Sánchez: Writing - review \& editing. 


\section{Declaration of Competing Interest}

The authors declare that they have no known competing financial interests or personal relationships that could have appeared to influence the work reported in this paper.

\section{References}

[1] C. Muñoz-Ruiperez, A. Rodríguez, S. Gutiêrrez-González, V. Calderón Lightweight masonry mortars made with expanded clay and recycled aggregates, Constr. Build. Mater. 118 (2016) 139-145, https://doi.org 10.1016/j.conbuildmat.2016.05.065.

[2] P. Villoria, J. Santa Cruz, R. Merino, M. del P. Mercader, A. Rodríguez, Estimation of construction and demolition waste in building energy eficiency retrofitting works of the vertical envelope, J. Cleaner Production. 172 (2018) 2978-2985, doi: $10.1016 /$ j.jclepro.2017.11.113.

[3] M.J. Morales-Conde, P. Rubio-de-Hita, F. Pérez-Gálvez, Composite Mortars produced with wood waste from demolition: assessment of new compounds with enhanced thermal properties, J. Mater. Civ. Eng. 30 (2018) 1-10, https:// doi.org/10.1061/(ASCE)MT.1943-5533.0002148.

[4] P. Piñeiro, A. García Pintos, Prácticas ambientales en el sector de la construcción. el caso de las empresas constructoras españolas, Investig. Eur. Dir. y Econ. La Empres. 15 (2009) 183-200, https://doi.org/10.1016/S11352523(12)60096-3.

[5] C. Luaces, El consumo de áridos creció un 10,5\% en 2017, hasta los 112 millones de toneladas, Cem. Hormigón. 987 (2018) 10-17.

[6] K. Kalinowska-Wichrowska, C. Piña, A. Vidales, Propuesta para reutilizar como agregado árido reciclado y residuos de material aislante. The second life of construction waste. Proposal to reuse recycled fine aggregate and residues of insulating materials, Anales de Edificación. 5 (2019) 1-8, https://doi.org/ 10.20868/ade.2019.4039.

[7] C. Piña, R. Merino, C. Viñas, A. Vidales, M. Kosior-kazberuk, Analysis of the mechanical behaviour of the cement mortars with additives of mineral wool fibres from recycling of CDW, Constr. Build. Mater. 210 (2020) 56-62, https:// doi.org/10.1016/j.conbuildmat.2019.03.062.

[8] F. González-Yunta, M. González-Cortina, F. Lasheras-Merino, Influencia del tratamiento " a fuego " en las características del estuco tradicional con cal Informes de la Construcción. 67 (2015) 1-8, https://doi.org/10.3989/ic.13.016.

[9] R.K. Ibrahim, R. Hamid, M.R. Taha, Fire resistance of high-volume fly ash mortars with nanosilica addition, Constr. Build. Mater. 36 (2012) 779-786, https://doi.org/10.1016/j.conbuildmat.2012.05.028.

[10] M.S. Morsy, H. Abbas, S.H. Alsayed, Behavior of blended cement mortars containing nano-metakaolin at elevated temperatures, Constr. Build. Mater. 35 (2012) 900-905, https://doi.org/10.1016/j.conbuildmat.2012.04.099.

[11] Q. Li, Z. Li, G. Yuan, Effects of elevated temperatures on properties of concrete containing ground granulated blast furnace slag as cementitious material, Constr. Build. Mater. 35 (2012) 687-692, https://doi.org/10.1016 j.conbuildmat.2012.04.103.

[12] H. Tanyildizi, A. Coskun, The effect of high temperature on compressive strength and splitting tensile strength of structural lightweight concrete containing fly ash, 22 (2008) 2269-2275, doi: 10.1016/ j.conbuildmat.2007.07.033.

[13] S. Aydın, Development of a high-temperature-resistant mortar by using slag and pumice, Fire Saf. J. 43 (2008) 610-617, https://doi.org/10.1016/ j.firesaf.2008.02.001.

[14] C. Galle, P. Kalifa, High-temperature behaviour of HPC with polypropylene fibres from spalling to microstructure, Cem. Concr. Res. 31 (2001) 1487-1499.

[15] M.L. Sánchez Paradela, V. Sănchez Gálvez, Comportamiento a tracción de cementos reforzados con fibras de vidrio, Informes de la Construcción. 43 (1991) 13.
[16] M. Ezziane, T. Kadri, L. Molez, R. Jauberthie, A. Belhacen, High temperature behaviour of polypropylene fi bres reinforced mortars, Fire Saf. J. 71 (2015) 324-331, https://doi.org/10.1016/j.firesaf.2014.11.022.

[17] D. Choumanidis, E. Badogiannis, P. Nomikos, A. Sofianos, The effect of different fibres on the flexural behaviour of concrete exposed to normal and elevated temperatures, Constr. Build. Mater. 129 (2016) 266-277, https://doi.org/ 10.1016/j.conbuildmat.2016.10.089.

[18] Y. Ding, C. Zhang, M. Cao, Y. Zhang, C. Azevedo, Influence of different fibers on the change of pore pressure of self-consolidating concrete exposed to fire, Constr. Build. Mater. 113 (2016) 456-469, https://doi.org/10.1016/ j.conbuildmat.2016.03.070.

[19] UNE-EN 197-1:2011, Cement - Part 1: Composition, specifications and conformity criteria for common cements, 2011.

[20] RC-08, Instrucción para la recepción de cementos. Con comentarios de los miembros de la Comisión Permanente del cemento, Secretaría Técnica, España, 2009.

[21] UNE-EN 13139/AC:2004, Aggregates for mortar, 2004

[22] UNE-EN 13279-2:2014, Gypsum binders and gypsum plasters - Part 2: Test methods, 2014

[23] C. Piña, E. Atanes, R. Merino, C. Viñas, A. Vidales, Feasibility of the use of mineral wool fibres recovered from $\mathrm{CDW}$ for the reinforcement of conglomerates by study of their porosity, Constr. Build. Mater. 191 (2020) 460-468, https://doi.org/10.1016/j.conbuildmat.2018.10.026.

[24] UNE-EN 1015-2:1999, Methods of test for mortar for masonry. Part 2: Bulk sampling of mortars and preparation of test mortars, 1999.

[25] UNE-EN 1015-11:2000, Methods of test for mortar for masonry. Part 11: Determination of flexural and compressive strength of hardened mortar, 2000.

[26] UNE-EN 1015-3:2000, Methods of test for mortar for masonry. Part 3: determination of consistence of fresh mortar (by flow table), 2000.

[27] UNE-EN 10204:2006, Metallic products - Types of inspection documents, 2006.

[28] UNE-EN ISO 10456:2001, Building materials and products. Procedures for determining declared and design thermal values, 2001.

[29] UNE-EN 1363-1:2015, Fire resistance tests - Part 1: General Requirements, 2015.

[30] UNE-EN 1363-2:2000, Fire resistance tests - Part 2: Alternative and additional procedures, 2000.

[31] UNE-EN 1365-4:2000, Fire resistance tests for loadbearing elements - Part 4: Columns, 2000

[32] ISO/TR 834-3:2012, Fire-resistance tests - Elements of building construction - Part 3: Commentary on test method and guide to the application of the outputs from the fire-resistance test, 2012.

[33] A. Bilodeau, V.K.R. Kodur, G.C. Hoff, Optimization of the type and amount of polypropylene fibres for preventing the spalling of lightweight concrete subjected to hydrocarbon fire, Cem. Concr. Compos. 26 (2004) 163-174, https://doi.org/10.1016/S0958-9465(03)00085-4.

[34] A.M. López-Buendía, M.D. Romero-Sánchez, V. Climent, C. Guillem, Surface treated polypropylene (PP) fibres for reinforced concrete, Cem. Concr. Res. 54 (2013) 29-35, https://doi.org/10.1016/j.cemconres.2013.08.004.

[35] R. Serrano, A. Cobo, M.I. Prieto, M. de N. González, Analysis of fire resistance of concrete with polypropylene or steel fibers, Constr. Build. Mater.122 (2016) 302-309, doi: 10.1016/j.conbuildmat.2016.06.055.

[36] UNE-EN 998-1:2010, Specification for mortar for masonry - Part 1: Rendering and plastering mortar, 2010

[37] D.K. Panesar, B. Shindman, The mechanical, transport and thermal properties of mortar and concrete containing waste cork, Cem. Concr. Compos. 34 (2012) 982-992, https://doi.org/10.1016/j.cemconcomp.2012.06.003.

[38] S.O.G. Ossenil, C. Ahouannoul, E.A. Sanyal, Y. Jannot, Investigation on the use of the cement mortar containing banana fibers as thermal insulator in building, Int. J. Adv. Res. 4 (2015) 1142-1152, https://doi.org/10.21474/JJAR01/2197. 